\title{
Comparative severity of experimentally induced mycobacteriosis in striped bass Morone saxatilis and hybrid tilapia Oreochromis spp.
}

\author{
J. C. Wolf, S. A. Smith* \\ Department of Biomedical Sciences and Pathobiology, Virginia-Maryland Regional College of Veterinary Medicine, \\ Virginia Polytechnic Institute and State University, Phase II, Duckpond Drive, Blacksburg, Virginia 24061-0442, USA
}

\begin{abstract}
Twenty striped bass Morone saxatilis and 20 hybrid tilapia Oreochromis niloticus $\times 0$. mossambicus $\times O$. aureus each received a single intramuscular injection of $1.6 \times 10^{6}$ colony forming units per gram body weight of Mycobacterium marinum. Striped bass manifested significantly greater clinical and microscopic disease compared to tilapia. Whereas all the striped bass had died or were clinically ill by Day 8 post-infection, there was no apparent disruption of normal behaviour, physical appearance, or growth in any of the sacrificed or surviving tilapia. Histologically, granulomas in striped bass were generally larger and less discrete, with a higher proportion of heavily vacuolated macrophages, and large cores of necrotic cells. Visceral granulomas in tilapia were smaller, with a higher proportion of epithelioid macrophages, more pigment-containing cells, more peripheral lymphocytes, and virtually no central necrosis. Visceral granulomas were 18 -fold more numerous in striped bass than in tilapia. Based upon histomorphometric data, mean proportions of acid-fast bacteria within pronephros granulomas were 4 -fold greater in striped bass than tilapia, and striped bass granulomas averaged more than twice as large as tilapia granulomas. In the anterior kidney of striped bass, a positive correlation existed between mean mycobacterial proportions and mean necrosis scores. In tilapia, mean mycobacterial proportions correlated negatively with mean granuloma numbers, whereas there was no correlation between these parameters in striped bass. Results suggest that intrinsic functional differences in the immunologic systems of striped bass and hybrid tilapia may contribute to inter-species variation in mycobacteriosis susceptibility.
\end{abstract}

KEY WORDS: Mycobacterium marinum - Striped bass - Tilapia - Resistance $\cdot$ Susceptibility

\section{INTRODUCTION}

Piscine mycobacteriosis is an insidious, gradually progressive disease of worldwide distribution that affects both cultured and natural populations of marine, brackish, and freshwater fish. In teleosts, mycobacteriosis is most commonly caused by 1 of 3 species of Gram-positive, aerobic, non-spore-forming, non-motile, pleomorphic acid-fast bacilli: Mycobacterium marinum, $M$. fortuitum, or $M$. chelonae (Dalsgaard et al. 1992, Hatai \& Lawhavinit 1993, Chen et al. 1997, Bruno et al. 1998). Both subclinically infected carrier fish and the environment may serve as reservoir sources of

-Addressee for correspondence. E-mail: stsmith7@vt.edu infection (Ross \& Johnson 1962, Nigrelli \& Vogel 1963, Snieszko 1978, Chinabut et al. 1990) and transmission is thought to occur mainly via ingestion of contaminated materials (Nigrelli \& Vogel 1963, Smith 1997) or through damaged skin or gill tissue (Dulin 1979). Factors that may predispose fish to mycobacterial infection include dietary or environmental contamination, stress associated with overcrowding, suboptimal nutrition, and poor water quality (Hedrick et al. 1987. Bragg et al. 1990, Smith 1997). Clinical signs of fish mycobacteriosis are non-specific, and include emaciation, anorexia, stunted growth, ascites, nervous disorders, exophthalmos, keratitis, dermal pigmentary changes, loss of scales, and skin ulcers (Snieszko 1978, Dulin 1979, Bragg et al. 1990, Grady et al. 1992, Smith 1997). Grossly evident internal lesions generally con- 
sist of single or multiple grey-white nodules or plaques (granulomas) within a variety of parenchymal organs, on serous surfaces, and occasionally in bone (Snieszko 1978, Dulin 1979, Bragg et al. 1990, Smith 1997). Because several Mycobacterium species are ubiquitous in aquatic environments, and effective therapy for infected fish does not exist, mycobacteriosis has the potential to profoundly impact commercial fisheries, sport fisheries, aquaculture enterprises, and public and private ornamental aquaria. Economically significant consequences of piscine mycobacteriosis include mortality, morbidity, and effects of subclinical infection such as decreased feed efficiency, decreased growth rates, and decreased marketability.

It has been proposed that any freshwater or marine fish can become infected by mycobacteria (Dulin 1979), a hypothesis supported by the study of Nigrelli \& Vogel (1963) in which mycobacteriosis was reported in over 150 species of aquarium fishes. Nevertheless, among published accounts of piscine mycobacteriosis, certain fish species appear overrepresented. For example, in recent years there have been several reports of mycobacteriosis in both captive and feral populations of striped bass (Sakanari et al. 1983, Hedrick et al. 1987, Lansdell et al. 1993, Smith et al. 1996, Baya et al. 1998, Vogelbein et al. 1999). Thus far, however, the evidence for clear differences in mycobacterial disease resistance among fishes is almost exclusively anecdotal. The purpose of this study was to examine the comparative clinical and microscopic responses of a putatively susceptible fish species, striped bass Morone saxatilis, and a putatively resistant fish, hybrid tilapia Oreochromis spp., to an experimentally induced infection of a fish pathogen (Mycobacterium marinum) under laboratory conditions.

\section{MATERIALS AND METHODS}

Pilot study in striped bass. A preliminary trial was performed to determine the optimum inoculation route and bacterial concentration for generating systemic mycobacterial infections in striped bass (the more susceptible fish species) within a reasonable time period. Striped bass fingerlings (average 3 to $4 \mathrm{~g}$ ) were divided into 10 groups of 5 fish each, and fish from each of 9 of the groups were exposed to Mycobacterium marinum (ATCC no. 927) at $10^{5}, 10^{6}$, or $10^{7}$ colony forming units (cfu) per fish by 1 of 3 routes: intramuscular injection (IM), gastric gavage, or bath immersion (reproducible laboratory simulations of natural exposure via dermal wound invasion, oral ingestion, and penetration of intact mucous membranes, respectively). Fish in the tenth group (sham-inoculated) received a comparable amount of vehicle (PBS-T) given IM. During the course of the trial, moribund fish were euthanatized. The trial was terminated $67 \mathrm{~d}$ after the bacterial inoculations.

Striped bass versus tilapia. One week prior to the start of the main experiment, 22 juvenile striped bass and 22 hybrid tilapia Oreochromis niloticus $\times$ O. mossambicus $\times O$. aureus of comparable age were arbitrarily selected from stocks maintained in the Aquatic Medicine Laboratory of the Virginia-Maryland Regional College of Veterinary Medicine, Blacksburg, Virginia, USA. The average weight of striped bass was $4.80 \mathrm{~g}$ (range: 3.01 to $7.11 \mathrm{~g}$ ), and the average weight of hybrid tilapia (hereafter referred to as tilapia) was $6.26 \mathrm{~g}$ (range: 3.39 to $11.36 \mathrm{~g}$ ). All fish were housed within the same room in 3 identical systems, each consisting of a $76 \mathrm{l}$ rectangular glass tank that was divided into 2 equal compartments by a perforated plastic partition. Each individual compartment contained a single box filter. Ten striped bass were placed into the first compartment of the first tank 10 were placed into the first compartment of the second tank, and 2 striped bass were placed into the first compartment of the third tank. In the same manner, the tilapia were distributed among the second compartments of each of the 3 tanks. Throughout the 1 wk acclimation period and $8 \mathrm{~d}$ experiment, concentrations of $\mathrm{pH}$, total ammonia, nitrite, nitrate, and alkalinity were monitored daily and maintained within acceptable limits. Water temperatures, measured daily, were kept between 23 and $24^{\circ} \mathrm{C}$, and the daily photoperiod consisted of $16 \mathrm{~h}$ of fluorescent light and $8 \mathrm{~h}$ darkness. Fish were fed floating pellets consisting of $41 \%$ protein (Zeigler Bros, Inc., Gardners, PA) at approximately $2 \%$ body weight once daily. To rule out the presence of concurrent disease or parasitic infestation prior to the start of the experiment, skin scrapings, gill biopsies, and histopathology were performed on representative samples of striped bass and tilapia.

Transmission of Mycobacterium marinum by intramuscular injection. Based upon results of the pilot study, an intramuscular route was chosen as the most dependable means of inducing generalized mycobacteriosis in striped bass within a relatively short time period (less than $3 \mathrm{wk}$ ). Nine days prior to the start of the experiment, sterile tubes containing $10 \mathrm{ml}$ of enriched Middlebrook $7 \mathrm{H} 9$ broth (Difco Laboratories, Detroit, MI) plus $5 \mathrm{mg}$ Tween 80 were inoculated with M. marinum (ATCC no. 927) and incubated at $25^{\circ} \mathrm{C}$. On Day 1 of the experiment, bacterial cells were washed 3 times in phosphate buffered saline $+0.5 \%$ Tween 80 (PBS-T), prior to a final resuspension in PBS-T. Based upon a curve derived from previously analyzed samples (authors' unpubl. data), the mycobacterial concentration of the solution was estimated by absorption spectrophotometry (e.g. for an $M$. marinum solution in the exponential growth phase, an optical density [OD] 
of 0.1 at $660 \mathrm{~nm}$ was approximately equivalent to $100 \mathrm{cfu}$ when diluted 1:200000). For confirmation of the mycobacterial concentration, 3 diluted $0.1 \mathrm{ml} \mathrm{sam-}$ ples of the same bacterial solution were plated on Middlebrook 7H11 agar (Remel, Lenexa, KS) for colony counts to be performed at a later time. Each of the 44 fish was individually anesthetized using tricaine methanesulfonate (MS-222, Sigma, St. Louis, MO) buffered 2:1 with sodium bicarbonate, and then weighed. Each of the fish in the first 2 tanks received a single IM injection of $0.025 \mathrm{ml}$ bacterial solution per gram body weight. All injections were given in the right dorsolateral musculature, posterior to the operculum and anterior to the dorsal fin. In a similar fashion, each control fish in the third tank was injected with sterile PBS-T. Following injection, fish were recovered from anaesthesia and returned to the tanks in which they had been housed. During the experimental period, fish were observed at $8 \mathrm{~h}$ intervals for changes in appetite or behaviour, and for external lesions. The experiment was ended when $10(50 \%)$ of the experimentally infected fish of 1 species had died. At that point, the remaining 10 infected fish of the same species, 10 infected fish of the other species, and all control fish were euthanatized by anesthetic overdose. Swab cultures taken from the anterior kidney of 1 moribund striped bass and 1 sacrificed tilapia were plated on Middlebrook $7 \mathrm{H} 11$ agar and maintained at $25^{\circ} \mathrm{C}$. Bacterial colonies suspected to be mycobacteria were confirmed by a modified polymerase chain reaction procedure (Talaat et al. 1995).

Tissue preparation for histopathology. Each of the sampled fish was fixed internally by an intraperitoneal injection of $10 \%$ neutral buffered formalin, and fixed externally by immersion in additional formalin for a period of at least $72 \mathrm{~h}$. For tissue processing, the preserved fish were bisected sagittally, so that each half could be positioned into a standard tissue cassette. The tissues were decalcified for $72 \mathrm{~h}$ in $26 \%$ formic acid (TBD-2, Shandon Lipshaw, Pittsburgh, PA), rinsed in tap water, and routinely processed for paraffin embedding. Sections were cut from each block at levels of 500 and $1500 \mu \mathrm{m}$ from the midline. As a result, 4 serial paramedian sagittal tissue sections ( 2 from the left body half and 2 from the right) were obtained from each fish. All 4 sections were stained with haematoxylin and eosin (HE), and examined by light microscopy. For each fish, one additional sagittal section, selected to include the pronephros, was stained using a modified Fite's procedure that did not include a counterstain.

Determination of granuloma numbers. All $\mathrm{HE}$ sections from Mycobacterium marinum-inoculated fish were used for counting visceral granulomas. For quantitative analysis, a granuloma was defined as a nodular aggregate of approximately 20 or more activated macrophages, with or without a central area of necrosis, a mantle of mature lymphocytes, or peripheral fibrous connective tissue. Histomorphologic characteristics of activated macrophages included cytoplasmic expansion with minimal to heavy vacuolization, nuclear enlargement, overt phagocytosis, and a tendency to cluster. Using a $4 \times$ or $10 \times$ objective, granulomas were tallied within the following ten organ systems/anatomic regions: abdominal cavity (including mesenteric pancreas and swimbladder), anterior kidney, brain, eye, gastro-intestinal tract, gill (including thyroid tissue and pseudobranch), heart (including the sinus venosus), hepatopancreas, posterior kidney and spleen. Subcutaneous or intramuscular granulomas, all of which appeared to be associated with injection sites, were not included. In organs where granulomas were particularly numerous (e.g. kidney, spleen, and liver), counting was facilitated by viewing the image on a television monitor. Because each histologic section did not necessarily contain all 10 organ systems, the total numbers of granulomas in each system was divided by the total number of instances in which the organ or region was observed to arrive at a mean value.

Determination of necrosis scores. Only HE sections from the 10 Mycobacterium marinum-inoculated striped bass were evaluated ( 40 sections total). The following scoring system was used to grade the percentage of necrotic granulomas within each anterior kidney: 1: $<25 \%$ necrotic; $2: 25$ to $50 \%$ necrotic; $3: 50$ to $75 \%$ necrotic 4 : $>75 \%$ necrotic. A mean necrosis score was calculated for each striped bass.

Determination of granuloma areas and bacterial proportions. Computer-assisted image analysis was employed to measure the proportion of acid-fast bacteria in anterior kidney granulomas of Mycobacterium marinum-inoculated striped bass versus tilapia. Analysis was based upon the ability of the software (Cue-3, ver. 3.4, Galai Production, Ltd., Industrial Zone, 10500 Migdal Haemek, Israel) to discern the red color of the Fite's-stained bacteria against a background of unstained tissue. The system (microscope, camera, computer) was calibrated according to the manufacturer's instructions. Colour threshold settings for objects were derived from the pixel colour values of acid-fast bacteria in renal granulomas, which were consistent from section to section and similar for the 2 fish species. For each of the 20 fish ( 10 striped bass and 10 tilapia), image evaluations at the $40 \times$ objective were performed on the 5 most cranial of the anterior kidney granulomas. Each granuloma was outlined as a field, and the total object area within each field (acid-fast bacteria) and the overall area of each field (granuloma) were measured (square microns). From this data, the percent area of each granuloma occupied by acid-fast 
bacteria (bacterial proportion) was determined. Mean granuloma areas and mean bacterial proportions were calculated for each fish.

Statistical analysis. Inter-species comparisons of granuloma numbers and bacterial proportions were analyzed using the unequal variance $t$-test of PROC TTEST of SAS (SAS ver. 6.12, SAS Institute, Inc., Cary, NC), whereas inter-species comparisons of granuloma areas were analyzed using the $t$-test for equal variance (SAS). Correlation analysis of granuloma numbers and bacterial proportions, performed individually for striped bass and tilapia, utilized Pearson correlation coefficients (SAS). Pearson coefficients were also used in correlation analysis of bacterial proportions and necrosis scores for the striped bass.

\section{RESULTS}

\section{Pilot study results}

Tank-wide morbidity and mortality was observed in the 3 groups of striped bass inoculated with Mycobacterium marinum by IM injection. The onset of severe malaise and spontaneous deaths occurred at $5 \mathrm{~d}$ for the high dose group (average $2.08 \times 10^{7} \mathrm{cfu}^{-1}$ ), $10 \mathrm{~d}$ for the medium dose group (average $1.93 \times 10^{6} \mathrm{cfu} \mathrm{g}^{-1}$ ), and $20 \mathrm{~d}$ for the low dose group (average $1.78 \times 10^{5} \mathrm{cfu}$ $\mathrm{g}^{-1}$ ) (Fig. 1). Consistently, the deaths were preceded by a few days of food refusal and lethargy, and by the appearance of shallow ulcers at injection sites. At each dose level, necropsy revealed nodular splenomegaly and renomegaly, and histologic evaluation revealed

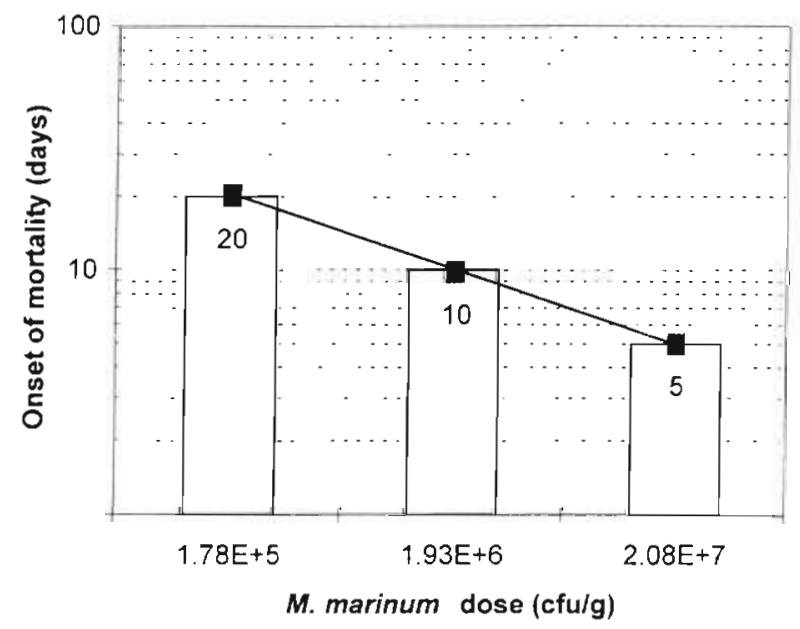

Fig. 1. Mycobacterium marinum infecting Morone saxatilis. Pilot study data. Days to onset of mortality in striped bass groups receiving 1 of 3 concentrations of $M$. marinum 927 given intramuscularly. Results are plotted on a logarithmic scale. There is a log inverse relationship between the $M$. marinum dose and the period of time prior to the onset of mortality severe, disseminated granulomatous inflammation with abundant acid-fast bacteria in all fish. Morbidity, mortality, and histological lesions were not evident in any of the striped bass from the gavage, bath, or control groups.

\section{Clinical signs and gross examination of striped bass versus tilapia}

On Day 4 post-inoculation (PI), experimentally infected striped bass ate hesitantly or refused food entirely. Conversely, the feeding patterns of the control striped bass and all tilapia were unchanged. By Day 7 PI, 3 infected striped bass were dead. Externally, 2 of the 3 deceased fish had multiple 1 to $2 \mathrm{~mm}$ red patches (petechial haemorrhage) on the operculum and around the eyes. The remaining 17 infected striped bass were crowded together, with their fins tightly clamped against their bodies. Some of these fish appeared disoriented in the water column and displayed aberrant swimming patterns. Slightly more than half of these infected bass had a 0.5 to $1 \mathrm{~cm}$ area of pale tan to purple discoloration and nodular swelling at the injection site, with or without 1 or more variably sized shallow irregular skin ulcers. In comparison, the experimentally infected tilapia displayed only mild swelling and erythema at injection sites, and sham-inoculated (PBS-T) control fish of both species appeared externally unblemished. By Day 8 , the remaining experimentally infected striped bass were completely anorexic, torpid, and had difficulty swimming. In sharp contrast, all the tilapia and the 2 control striped bass still appeared behaviorally and physically unaltered. The experiment was terminated on Day 8 following the death of 7 additional infected striped bass (cumulative $50 \%$ mortality). Internal examination of the infected striped bass consistently revealed moderate to marked splenomegaly, and often renomegaly. Splenic surfaces were frequently studded by pale nodules $<1 \mathrm{~mm}$ diameter. In contrast, tilapia were grossly unremarkable. Interestingly, of the 9 tilapia that were not sacrificed at the end of this experiment, 8 remain alive without clinical signs of disease approximately 9 mo PI (necropsy was not performed on the ninth fish due to the cannibalized state of the carcass).

\section{Bacteriology and PCR}

Colony counts revealed that the injected mycobacterial solution contained $6.4 \times 10^{7} \mathrm{cfu} \mathrm{ml^{-1 }}$. Thus, each fish received $1.6 \times 10^{6} \mathrm{cfu}$ of Mycobacterium marinum per gram body weight. Following 8 to $10 \mathrm{~d}$ of incubation, anterior kidney cultures from the $M$. marinum- 
inoculated striped bass and tilapia yielded morphologically similar small to medium-sized buff-colored bacterial colonies, with scalloped edges and slightly raised granular centres. Whereas the striped bass culture resulted in a dense mat of bacteria, only a few such colonies were evident in the sample obtained from the tilapia. Appropriately sized bands (924 base pair) were generated by PCR from bacterial DNA samples obtained from both fish species, supporting their identification as mycobacteria (Talaat et al. 1995).

\section{Histopathologic findings common to striped bass and tilapia}

Microscopically, infected individuals of both fish species exhibited varying degrees of granulomatous inflammation within the intramuscular injection site and various abdominal viscera. In Fite's-stained sections, acid-fast bacteria were present in virtually all areas of granulomatous inflammation. Mineralization was not evident in granulomas of either species, and multinucleated giant cells were observed only rarely in striped bass tissues. There were no grossly or histologically apparent intramuscular or visceral lesions in sham-inoculated control striped bass or tilapia.

\section{Histopathologic changes distinctive to striped bass versus tilapia}

Although visceral granulomas were present in both fish species, the severity, distribution, and character of the inflammatory response differed greatly between striped bass and tilapia. Compared to tilapia, the inflammatory response within striped bass was more severe. At each injection site in the striped bass, vast aggregates of foamy (heavily vacuolated) macrophages were accompanied by areas of skeletal muscle necrosis (Fig. 2), which invariably contained myriads of extracellular acid-fast bacilli. Relative to tilapia, the muscle lesions of striped bass featured fewer lymphocytes. In the anterior kidney and spleen of the striped bass, the parenchyma was essentially replaced by coalescing granulomas, 75 to $250 \mu \mathrm{m}$ diameter. These granulomas typically had cores of necrotic cells and eosinophilic cellular debris enveloped by narrow rims of foamy macrophages (Fig. 4). Lesser numbers of smaller granulomas were comprised of solid clusters of foamy macrophages. Occasionally, renal and splenic granulomas were surrounded by 1 or 2 rings of flattened cells resembling fibroblasts. These flattened cells were not accompanied by appreciable collagenous material. Central necrosis was also a consistent finding in the miliary granulomata of the hepatopancreas, pos- terior kidney, and abdominal mesentery. Within the heart and gill lamellae, granulomas generally consisted of macrophages in loose irregular aggregates.

In tilapia, inflammation was mild to moderate. At each injection site, well-defined, patchy macrophage aggregates were surrounded by moderate numbers of lymphocytes and occasional heterophils (Fig. 3). Injection site macrophages often contained packets of 1.5 to $2 \mu \mathrm{m}$ length, faint basophilic bacilli within large intracytoplasmic vacuoles. These bacteria were consistently acid-fast positive in Fite's-stained sections. Within abdominal viscera, the inflammation was milder compared to the injection sites. Scattered, 50 to $100 \mu \mathrm{m}$ diameter, paucibacillary, intra-abdominal granulomata consisted of densely packed epithelioid and foamy macrophages in discrete clusters (Fig. 5). Often, a large percentage of these cells contained variable amounts of dark brown pigment, suggesting that they may have been of melanomacrophage origin. Necrosis was not characteristic of granulomas in the tilapia, and damage to adjacent tissues was minimal.

\section{Quantitative analysis}

The mean number of granulomas per organ system was approximately 18-fold higher in striped bass compared to tilapia (Table 1). Striped bass had a higher number of granulomas per observation in each of the individual tissues or organ systems, which was significant in all organs ( $p=0.0001$ to 0.01 ) except for the eye $(\mathrm{p}=0.184$ ) (Fig. 8). In striped bass, the greatest numbers of granulomas were found in the spleen $(28.8 \%)$, hepatopancreas $(27.0 \%)$, anterior kidney $(19.5 \%)$, posterior kidney ( $8.2 \%)$, abdominal cavity (7.6\%) and heart $(5.2 \%)$. By comparison, tilapia granulomas were less well distributed, with the majority occurring in the anterior kidney $(49.0 \%)$ and spleen (38.6\%), followed distantly by the eye $(6.8 \%)$ and abdominal cavity $(3.9 \%)$. Image analysis of Fite's-stained sections revealed that striped bass renal granulomas contained approximately 4 -fold higher proportions of acid-fast bacteria on average compared to tilapia renal granulomas $(34.4 \%$ vs $8.1 \% ; \mathrm{p}=0.0002)$. Additionally, striped bass granulomas were more than twice as large as tilapia granulomas $\left(7967.1 \mu^{2}\right.$ vs $3256.9{\mu m^{2}}^{2}$ p $=$ 0.0000 ). Such measurements were consistent with the general histologic appearance of tilapia and striped bass granulomas (Figs. $6 \& 7$ ). In striped bass, there was a positive correlation ( $\mathrm{r}=0.793 ; \mathrm{p}=0.006$ ) between bacterial proportions and necrosis scores. In tilapia, there was a negative correlation between granuloma numbers and bacterial proportions ( $\mathrm{r}=-0.819$; $p=0.004$ ), whereas there was no correlation between these parameters in striped bass $(r=0.461 ; p=0.180)$. 


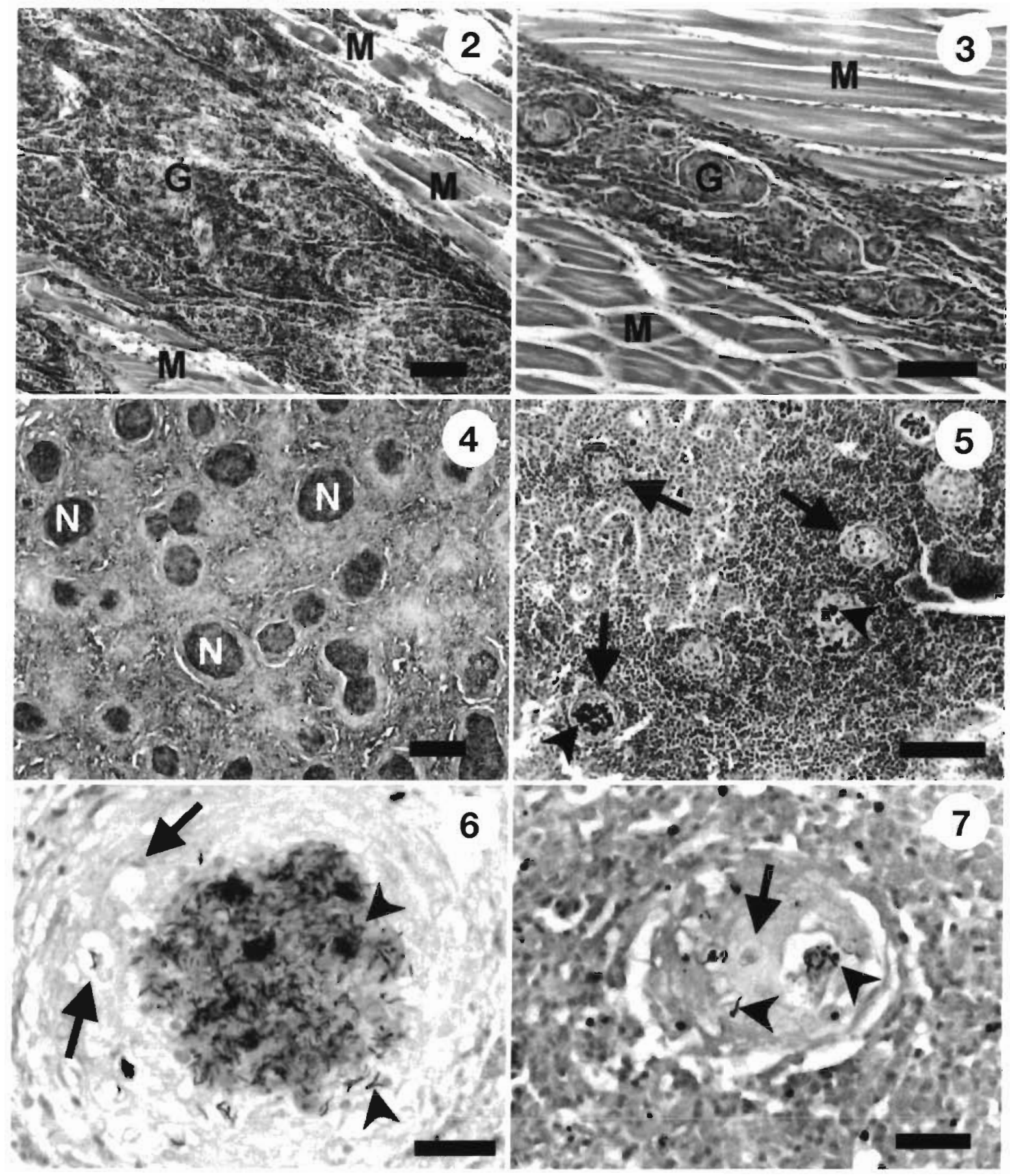

Figs. 2 to 7. Light microscopic comparison of lesions from Mycobacterium marinum-inoculated striped bass Morone saxatilis and hybrid tilapia Oreochromis spp. Fig. 2. Representative intramuscular (IM) injection site from a striped bass. Poorly defined areas of granulomatous inflammation (G) are surrounded by necrotic skeletal muscle (M). Fite's staining revealed massive numbers of intracellular and extracellular acid-fast bacteria throughout this field. HE, scale bar $=100 \mu \mathrm{m}$. Fig. 3. Representative IM injection site from a tilapia. Discrete granulomas $(G)$ are accompanied by macrophages and lymphocytes peripherally. Surrounding muscle (M) appears unperturbed. Acid-fast bacteria (not visible on HE) are primarily intracellular. HE, scale bar $=100 \mu \mathrm{m}$. Fig. 4 . Striped bass hemopoietic tissue (spleen). Splenic parenchyma is replaced by coalescing granulomas, most of which have necrotic centers (N). HE, scale bar $=100 \mu \mathrm{m}$. Fig. 5. Tilapia hemopoietic and interrenal tissues (anterior kidney). Small isolated granulomas (arrows) often contain brown pigment and pigment laden cells (arrowheads). Necrosis was not a feature of granulomas in tilapia. HE, scale bar $=100 \mu \mathrm{m}$. Fig. 6. Striped bass renal granuloma. Heavily vacuolated macrophages (arrows) encircle abundant acid-fast bacilli (arrowheads). Fite's, scale bar $=25 \mu \mathrm{m}$. Fig. 7 . Tilapia renal granuloma. Epithelioid macrophages (arrow) enclose comparatively fewer acid-fast bacteria (arrowheads). Fite's, scale bar $=25 \mu \mathrm{m}$ 
Table 1. Mycobacterium marinum infecting Morone saxatilis and Oreochromis spp. Comparison of granuloma numbers, granuloma areas, and bacterial proportions from $M$. marinuminoculated striped bass and tilapia (mean $\pm \mathrm{SE}$ )

\begin{tabular}{|lrcc|}
\hline Species & $\begin{array}{c}\text { Granulomas } \\
\text { perorgan }\end{array}$ & $\begin{array}{c}\text { Granuloma } \\
\text { area }\left(\mu \mathrm{m}^{2}\right)\end{array}$ & $\begin{array}{c}\text { Bacterial } \\
\text { proportion }(\%)\end{array}$ \\
\hline Striped bass & $38.0 \pm 7.5$ & $7967.1 \pm 744.4$ & $34.4 \pm 6.3$ \\
Hybrid tilapia & $2.1 \pm 0.7$ & $3256.9 \pm 443.4$ & $8.1 \pm 1.5$ \\
\hline
\end{tabular}

\section{DISCUSSION}

Infectious disease resistance employs both nonspecific and specific host defense mechanisms. Nonspecific defenses include intact dermal and mucosal barriers, cytotoxic and phagocytic leukocytes, and the generation of antimicrobial substances such as complement or lysozyme, whereas specific defenses involve the lymphocyte-based humoral and cellular immune systems (Chen et al. 1996). Genetic factors modulate both types of mechanisms, and thus affect individual, strain, or species susceptibility to infection. Genetic factors shown to influence susceptibility to mycobacteriosis in rodents and humans include sequence variations in genes responsible for the Nramp1 locus (Buschman et al. 1997), HLA-subtypes (Meyers \& Marty 1991), and deficiencies in receptors for interferon-gamma (Newport et al. 1996) and interleukin-12 (Altare et al. 1998). Among mammals, inter-species variation in mycobacterial resistance is well-recognized. For example, it has been observed that cats, dogs, monkeys, and healthy humans are refractory to Mycobacterium avium, whereas, mink, rabbits, and swine are readily infected by this pathogen (Karlson 1978). Another mycobacterium, Mycobacterium leprae, appears to be even more hostselective, as spontaneous cases of leprosy have been entirely limited to humans, non-human primates, and nine-banded armadillos (Meyers \& Marty 1991). Based upon these examples, we hypothesized that susceptibility to mycobacteriosis might also vary among the greater than 15000 morphologically and genetically diverse species of teleost fish.

In the present study, mycobacteria appeared to proliferate and spread almost unchecked throughout the tissues of experimentally infected striped bass. This process occurred despite an intense necrogranulomatous inflammatory response that resulted in considerable damage to vital organs, invariably leading to the debilitation and death of affected fish. Conversely, experimental Mycobacterium marinum infections in tilapia were effectively contained by fewer, smaller, and comparably benign granulomata. The significantly lower concentration of acid-fast bacteria in tilapia
Fig. 8. Mycobacterium marinum infecting Morone saxatilis and Oreochromis spp. Distribution of granulomas among organ systems in $M$. marinum-inoculated striped bass and tilapia (mean \pm $\mathrm{SE})$. Beneath each column is the total number of histologic sections in which the organ system was observed

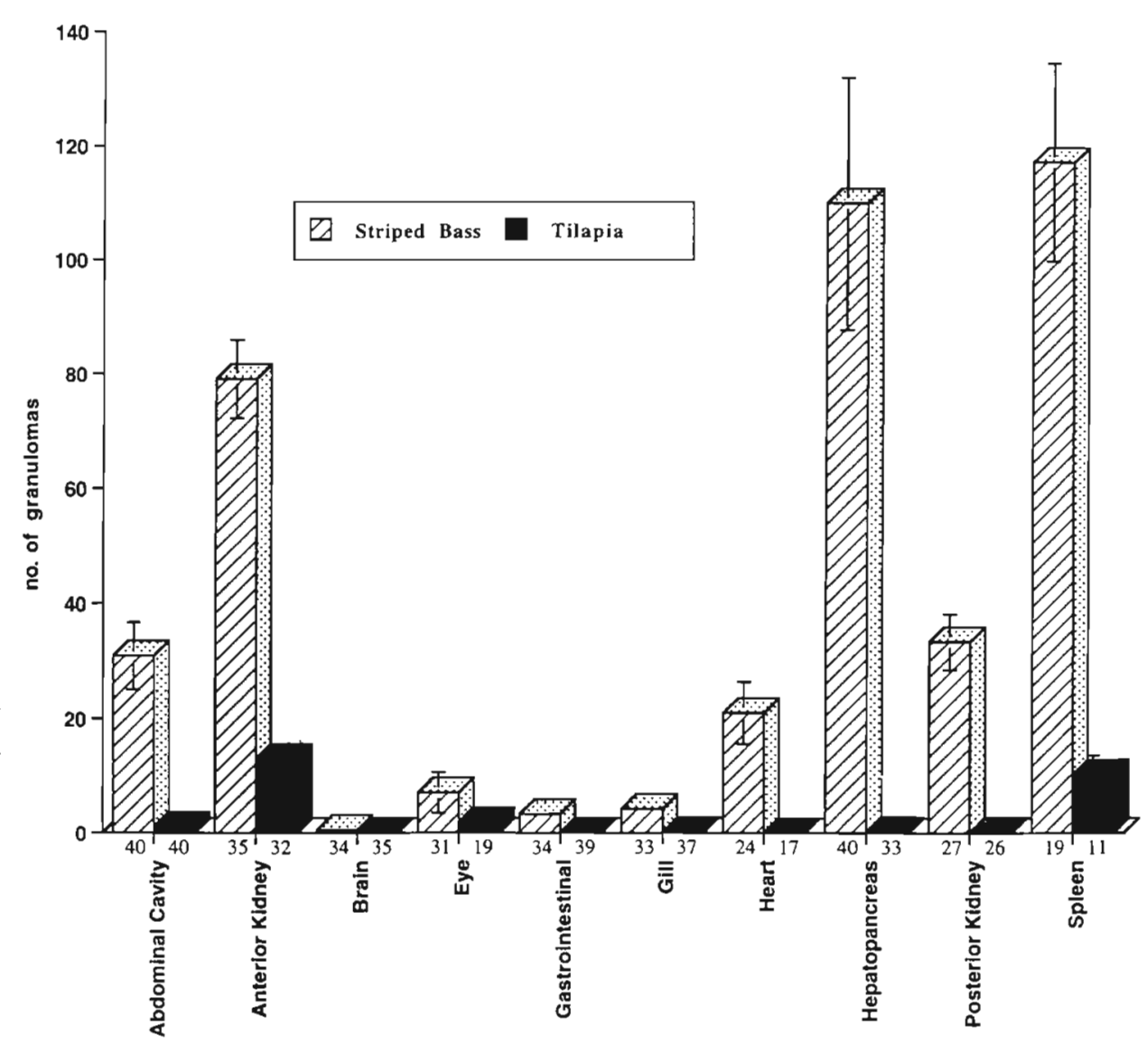


granulomas compared to those of striped bass suggests that the antimicrobial defense systems of tilapia were more efficient at controlling the survival, multiplication, and/or dissemination of $M$. marinum. How and when this control occurs is unknown. One possibility is that enhanced killing of mycobacteria (by phagocytes or by nonspecific cytotoxic cells) (Jaso-Friedman \& Evans 1999) may have occurred at the IM injection site or hematogenously in tilapia, thus limiting the initial spread of mycobacteria. Consequently, the comparably smaller size of tilapia visceral granulomas could be attributed to reduced bacteraemic seeding of internal organs. This theory is supported by the relative paucity of granulomas that were found in tilapia tissues other than the anterior kidney, spleen, and eye. Alternatively, tilapia might have gained an advantage during the later stages of infection; for example, antigen-presenting cells within target tissues such as the kidney and spleen may have been more efficient at processing and displaying mycobacterial antigens compared to their striped bass counterparts. The lack of central necrosis in the tilapia granulomas may also be a function of bacterial numbers. Among the striped bass, a positive correlation existed between the concentration (proportion) of acid-fast bacteria within anterior kidney granulomas, and the scored percentage of necrotic pronephros granulomas. One possible reason for this correlation is that non-caseated necrotic tissue represents a favorable medium for mycobacterial replication (Dannenberg Jr 1991, Rook \& Hernandez-Pando 1996). Another hypothesis is that bacterial overload may have been responsiole for the death of macrophages within the centers of striped bass granulomas. Mycobacteria are thought to produce few hystiolytic enzymes (Samuelson \& Von Lichtenberg 1994, Chen et al. 1997); nevertheless, there are several mechanisms by which mycobacteria may be lethal to macrophages, including stimulation of delayed-type hypersensitivity resulting in macrophage destruction by $\mathrm{T}$ lymphocytes (Dannenberg Jr 1991, Bloom et al. 1994, Hines et al. 1995), cytotoxicity caused by lymphocyte-secreted TNF- $\alpha$ (Rook \& Hernandez-Pando 1996), macrophage lysis due to the indigestibility (Colorni 1992) or multiplication (Dannenberg $J_{r}$ 1991) of intracellular bacteria, induction of macrophage apoptosis (Rojas et al. 1997), and direct toxic effects (Samuelson \& Von Lichtenberg 1994, Rook \& Hernandez-Pando 1996). Additionally, lysozyme released by dying macrophages probably contributes to the demise of neighboring cells (Chen et al. 1996).

One unanticipated result of the striped bass versus tilapia experiment was the negative correlation observed between bacterial proportions and granuloma numbers in tilapia. A possible explanation is that tilapia phagocyte performance may have been enhanced in more highly disseminated infections, resulting in more efficient bacterial killing. This type of enhancement could have been caused by increased upregulation of stimulatory cytokines such as macrophage activating factor (a putative piscine interferon-gamma analogue) (Graham \& Secombes 4988,1990 ). Notably, a similar correlation between granuloma numbers and bacterial proportions was not evident in the striped bass. In the pilot study, another unexpected outcome was our inability to generate systemic mycobacteriosis in striped bass by gastric gavage. This result was interesting but not unprecedented; in a previous study, 3 of 4 groups of goldfish and platyfish failed to manifest disease signs or histological evidence of infection following experimental exposure to 2 different fish-derived isolates of acid-fast bacteria that were mixed with feed (Baker \& Hagan 1942). Results of that study suggest that oral infectivity is determined (at least in part) by the strain or species of acid-fast organism and the species of fish to be infected.

Talaat et. al (1998) reported that the $50 \%$ lethal dose $\left(\mathrm{LD}^{50}\right)$ for Mycobacterium marinum 927 in goldfish was $4.5 \times 10^{8} \mathrm{cfu}$ at $1 \mathrm{wk}$ PI. Given that the average weight of their experimental goldfish was $25 \mathrm{~g}$, this is equivalent to $1.8 \times 10^{7} \mathrm{cfu} \mathrm{g}^{-1}$ body weight. Based upon the single IM treatment group from our experiments, the $L_{50}$ of $M$. marinum 927 for striped bass at $8 \mathrm{~d}$ PI was $1.6 \times 10^{6} \mathrm{cfu} \mathrm{g}^{-1}$ body weight, a value that is approximately 10 -fold less than the goldfish result. Thus, it would appear that goldfish may be more resistant to $M$. marinum infection compared to striped bass. However, the validity of a direct comparison between the goldfish and striped bass data is questionable, because the goldfish were inoculated intraperitoneally rather than by the IM route. Other confounding factors may have included differences in water temperature and stocking density, and the presence or absence of concurrent disease.

In a broad sense, the results of the present investigation are consistent with prior accounts of mycobacteriosis in striped bass and tilapia. Whereas, significant mortality $(50 \%)$ was observed in an outbreak of mycobacteriosis in cuitured striped bass (Hedrick et al. 1987), the only clinical signs associated with Mycobacterium marinum infection in tilapia were changes in skin pigmentation, dermal ulcers, fin necrosis, and decreased growth rate (Noga et al. 1990). Although the decisive outcome of our experiment suggests that striped bass are more susceptible to mycobacteriosis compared to tilapia, interpretation of the data must be made cautiously. Future work will determine whether the present study's results are reproducible under various experimental conditions, for different strains of tilapia and striped bass, or for different species and strains of mycobacteria. In this regard, the IM inocula- 
tion model should continue to prove useful for studying the progression of piscine mycobacteriosis, since this technique predictably induces dose-responsive systemic infections in striped bass. Likewise, the quantitative methods used in this study may be valuable in future experiments, as such measurements provide an objective basis for comparing levels of mycobacterial infection and disease among different treatment groups or species of fish.

In the present study, inter-species variation in the morbidity, mortality, and histologic appearance of the inflammatory lesions are indications that there may be intrinsic differences (e.g. antigen presentation, phagocyte killing, intercellular signaling) between striped bass and tilapia in their immune responses to mycobacterial infection. If the factor(s) governing differential susceptibility to piscine mycobacteriosis could be determined, it/they could be used to screen broodstock for resistance, and ultimately, identify and select genetically resistant fish strains. Additionally, the value of such research is underscored by the concept that the same factors might also participate in resistance to other intracellular fish pathogens.

Acknowledgements. The authors would like to thank Dr John Robertson, Dr Steven Holladay, Mary Ellen Berger, Amornchai Somjetlertcharoen, Cynthia Tate, and Dan Hall for their technical assistance. We would also like to thank Dr Robert Duncan for his critical review. This study was supported in part by the Cooperative State Research Service, U. S. Department of Agriculture under project No. VA 123348, and by the Virginia Sea Grant College Program project No. R/A 28

\section{LITERATURE CITED}

Altare F, Durandy A, Lammas D, Emile JF, Lamhamedi S, Le Deist $F$, Drysdale $P$, Jouanguy $E$, Doffinger $R$, Bernaudin F, Jeppsson O, Gollob J, Meinl E, Segal A, Fischer A, Kumararatne D, Casanova JL (1998) Impairment of mycobacterial immunity in human interleukin- 12 receptor deficiency. Science 280:1432-1435

Baker JA, Hagan WA (1942) Tuberculosis of the Mexican platyfish (Platypoecilus maculatus). J Infect Dis 70: 248-252

Baya A, May EB, Li T, Weedon C, Peiper L, Huang J, Blazer V, Reimshuessel R (1998) Mycobacteria-a possible emerging pathogen of striped bass caught in the Maryland portion of the Chesapeake Bay. In: Kane AS, Poynton SL (eds) Third International Symposium on Aquatic Animal Health. APC Press, Baltimore, MD

Bloom BR, Flynn J, McDonough K, Kress Y, Chan J (1994) Experimental approaches to mechanisms of protection and pathogenesis in $M$. tuberculosis infection. Immunobiology 191:526-536

Bragg RR, Huchzermeyer HF, Hanisch MA (1990) Mycobacterium fortuitum isolated from three species of fish in South Africa. Onderstepoort J Vet Res 57:101-102

Bruno DW, Griffiths J, Mitchell CG, Wood BP, Fletcher ZJ, Drobniewski FA, Hastings IS (1998) Pathology attributed to Mycobacterium chelonae infection among farmed and laboratory infected Atlantic salmon Salmo salar. Dis Aquat Org 33:101-109

Buschman E, Vidal S, Skamene E (1997) Nonspecific resistance to mycobacteria: the role of the Nramp1 gene. Behring Inst Mitt 99:51-57

Chen SC, Yoshida T, Adams A, Thompson KD, Richards RH (1996) lmmune response of rainbow trout to extracellular products of Mycobacterium spp. J Aquat Anim Health $8: 216-222$

Chen SC, Adams A, Richards RH (1997) Extracellular products from Mycabacterium spp. in fish. J Fish Dis 20: $19-25$

Chinabut S, Limsuwan C, Chanratchakool P (1990) Mycobacteriosis in the snakehead, Channa striatus (Fowler). J Fish Dis 13:531-535

Colorni A (1992) A systemic mycobacteriosis in the european sea bass Dicentrarchus labrax cultured in Eilat (Red Sea). Isr J Aquacult Bamidgeh 44:75-81

Dalsgaard I, Mellergaard S, Larsen JL (1992) Mycobacteriosis in cod (Gadus morhua L.) in Danish coastal waters. Aquaculture 107:211-219

Dannenberg Jr AM (1991) Delayed-type hypersensitivity and cell-mediated immunity in the pathogenesis of tuberculosis. Immunol Today 12:228-233

Dulin MP (1979) A review of tuberculosis (mycobacteriosis) in fish. Vet Med Small Anim Clin 74:731-735

Grady AW, Wolff A, Besch-Williford C (1992) Diagnostic exercise: visceral granulomas in a fish. Lab Anim Sci 42: 316-317

Graham S, Secombes CJ (1988) The production of a macrophage-activating factor from rainbow trout Salmo gairdneri leukocytes. Dev Comp Immunol 65:293-297

Graham S, Secombes CJ (1990) Do fish lymphocytes secrete IFN- $\gamma$ ? J Fish Biol 36:563-573

Hatai K, Lawhavinit O (1993) Mycobacterium infection in pejerrey, Odonthestes bonariensis Cuvier and Valenciennes. J Fish Dis 16:397-402

Hedrick RP, McDowell T, Groff J (1987) Mycobacteriosis in cultured striped bass from California. J Wild Dis 23: 391-395

Hines ME, Kreeger JM, Herron AJ (1995) Mycobacterial infections of animals: pathology and pathogenesis. Lab Animal Sci 45:334-351

Jaso-Friedman L, Evans DL (1999) Mechanisms of cellular cytotoxic innate resistance in tilapia (Oreochromis nilotica). Dev Comp Immunol 23:27-35

Karlson AG (1978) Avian tuberculosis. In: Montali RJ (ed) Mycobacterial infections of zoo animals. Smithsonian Press, Washington, DC, p 21

Lansdell W, Dixon B, Smith N, Benjamin L (1993) Isolation of several Mycobacterium species from fish. J Aquat Anim Health 5:73-76

Meyers WM, Marty AM (1991) Current concepts in the pathogenesis of leprosy. Drugs 41:832-856

Newport MJ, Huxley CM, Huston S, Hawrylowicz CM, Oostra BA, Williamson $R$, Levin $M$ (1996) A mutation in the interferon-gamma-receptor gene and susceptibility to mycobacterial infection. N Engl J Med 335:1941-1949

Nigrelli RF, Vogel H (1963) Spontaneous tuberculosis in fishes and other cold-blooded vertebrates with special reference to Mycobacterium fortuitum Cruz from fish and human lesions. Zoologica (NY) 48:131-143

Noga EJ, Wright JF, Pasarell L. (1990) Some unusual features of mycobacteriosis in the cichlid fish Oreochromis mossambicus. J Comp Pathol 102:335-344

Rojas M, Barrera LF, Puzo G, Garcia LF (1997) Differential induction of apoptosis by virulent Mycobacterium tuber- 
culosis in resistant and susceptible murine macrophages role of nitric oxide and mycobacterial products. J Immunol 159:1352-1361

Rook GAW, Hernandez-Pando R (1996) The pathogenesis of tuberculosis. Annu Rev Microbiol 50:259-284

Ross AJ, Johnson HE (1962) Studies of transmission of mycobacterial infections in Chinook salmon. Prog Fish-Cult 24: $147-149$

Sakanari JA, Reilly CA, Moser M (1983) Tubercular lesions in Pacific coast populations of striped bass. Trans Am Fish Soc 112:565-566

Samuelson J, Von Lichtenberg F (1994) Infectious diseases. In: Cotran RS, Kumar V, Robbins SL, Schoen FJ (eds) Pathologic basis of disease. WB Saunders Company, Philadelphia, p 305-377

Smith SA (1997) Mycobacterial infections in pet fish. Sem Avian Exot Pet Med 6:40-45

Smith SA, Holladay SD, Robertson JL (1996) Correlation of

Editorial responsibility: David Bruno,

Aberdeen, Scotland, UK pathology and immune reactivity of splenic tissue of hybrid striped bass infected with Mycobacterium sp. In: Abt DA (ed) International Association for Aquatic Animal Medicine Proceedings, Chattanooga, TN

Snieszko SF (1978) Mycobacteriosis (tuberculosis) of fishes West Virginia. US Fish and Wildlife Service, Kearneys ville, Fish Disease Leaflet 55, p 3-4

Talaat A, Reimschuessel $R$, Trucksis M (1995) The detection of pathogenic fish Mycobacterium using polymerase chain reaction. Abstr Annu Meet Am Soc Microbiol 95:132

Talaat AM, Reimschuessel R, Wasserman SS, Trucksis M (1998) Goldfish, Carassius auratus, a novel animal model for the study of Mycobacterium marinum pathogenesis. Infect Immun 66:2938-2942

Vogelbein WK, Zwerner DE, Kator H, Rhodes M, Cardinal J (1999) Epizootic mycobacteriosis in Chesapeake Bay striped bass. In: Cipriano RC (ed) 24th Annual Eastern Fish Health Workshop, Atlantic Beach, NC

Submitted: June 4, 1999; Accepted: August 26, 1999 Proofs received from author(s): November 11, 1999 